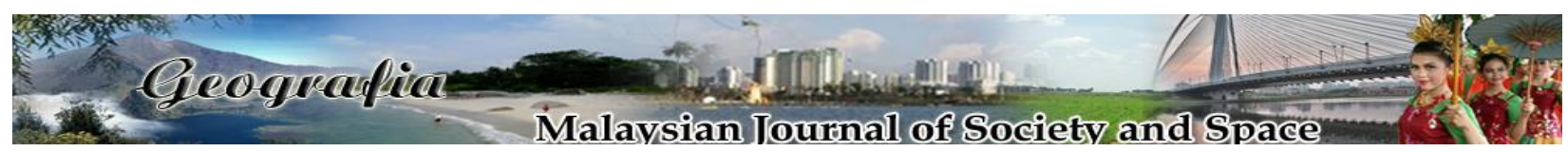

\title{
The interaction effects of knowledge transfer on knowledge assets and innovative performance relationship
}

\author{
Norhafizah Abu Hasan ${ }^{1}$, Nor Asiah Omar ${ }^{2}$, Muhammad Nizam Zainuddin ${ }^{3}$, Dzulkifli Mukhtar ${ }^{4}$ \\ ${ }^{1,2}$ Center of Value Creation and Human Well-being (INSAN), Faculty of Economy and Management, \\ Universiti Kebangsaan Malaysia \\ ${ }^{3}$ Centre of Excellence for Knowledge and Innovation Management (CEKIM), Faculty of Management, \\ Multimedia University, Malaysia \\ ${ }^{4}$ Faculty of Entrepreneurship and Business, Universiti Malaysia Kelantan, Malaysia
}

Correspondence: Norhafizah Abu Hasan (email: norhafizah1@ukm.edu.my)

Received: 30 January 2020; Accepted: 06 October 2020; Published: 29 November 2020

\begin{abstract}
The purpose of the present study is to empirically test the relationship among knowledge assets, such as explicit and tacit knowledge on SMEs' innovative performance. Furthermore, the contingent effects of speed, reliability and accuracy of knowledge transfer are also tested on the relationship. In which the theoretical framework was used to explain the Nonaka's theory of knowledge creation and knowledge-based view theory. This is because the present study is conducted to evaluate a direct relationship between knowledge assets on innovative performance. Thus, the contingent effect of knowledge transfer on the aforementioned relationship was tested. In order to achieve the study aims, the used of a quantitative study was employed via online questionnaires sent to SMEs. Multiple regression and interaction effect tests were utilised using SPSS25 software. The findings revealed three important outcomes. Firstly, knowledge assets have positive relationship with innovative performance. Secondly, speed of knowledge transfer positively influences knowledge assets and innovative performance relationship. Thirdly, reliability and accuracy of knowledge transfer also positively influence knowledge assets and innovative performance relationship. This result demonstrates that with the right management of knowledge, especially in making sure that knowledge is transferred to the right people, innovative performance especially in SMEs can be elevated.
\end{abstract}

Keywords: Innovation performance, knowledge assets, knowledge management, knowledge transfer. 


\section{Introduction}

Recently, the need for sustaining competitive advantage is very critical for business organisations. Organisations that value knowledge, both tacit and explicit, usually manage valuable resources that can sustain competitive advantage. Knowledge assets are the accumulated intellectual resources in the organisations in the form of ideas, experiences, information, memory, skills, understanding, learning, insights and abilities. It related resources are well known as important strategic assets that contribute to better organisational performance. According to knowledge-based view of the firm (Grant, 1996a), value creation occurs when organisation is able to manage knowledge. This involves knowledge sharing, knowledge transfer and finding ways to minimise imitation of innovative product or services created by the people in the company (Gast, Gundolf, Harms \& Matos Collado, 2019; Jantunen, 2005; Teece, 2000).

Knowledge management is a systematic process of acquisition, extraction, organisation and dissemination of knowledge in any organisation (Ahmad, JianMing \& Rafi, 2019). Past studies on transferring knowledge for innovation have debated whether knowledge is a strategic asset (Alexander, Neyer \& Huizingh, 2016). The research suggested 'Knowledge-based Management' and 'Strategic Knowledge Management' as two contributory elements. Furthermore, knowledge-based management is the 'hard' system, which is more technologically driven that is rooted from information technology and system. On the other hand, strategic knowledge management originated from the 'soft' theories that link with resource-based view of the firm (Barney, 1995), knowledge-based view (Grant, 1996b), and dynamic capabilities (Teece, Pisano \& Shuen, 1997). Many authors (Blomkvist, 2012; Reich, Gemino \& Sauer, 2014) found positive association between knowledge management and organisational performance to be a types of performances that varies from financial to innovative performance. Also, previous studies have found that proper management of knowledge in business organisation improves employees' creativity and elevates innovative performance (Chen, Wu \& Chen, 2014; Estrada, Faems \& de Faria, 2014; Roxas, Battisti \& Deakins, 2014).

However, the present study focuses on the management of knowledge assets in SMEs that is believed can improve innovative performance. Knowledge is one of the main assets in today's highly competitive business environment. Despite the growing body of research in knowledge assets (Amin, Usman, Sohail \& Aslam, 2018; Chung \& Yoon, 2015; Hasan, Hamzah, Saleh \& Kamaluddin, 2019; Lerro, Iacobone, \& Schiuma, 2012; Lin, Li, \& Wu, 2018), several deficiencies in the literature need to be addressed. Firstly, despite many studies have highlighted the importance of knowledge, yet most scholars recognised it simply as object that resides in the mind of individuals (Nonaka, 1994). Secondly, studies in the field of knowledge management lack the exploring the dynamic social interaction and sharing of information among people in the organisation. Thirdly, issues of governance and leadership in managing knowledge assets in organisations are scarce (Hasan et al., 2019).As such, literature review showed that most studies only focused on knowledge management from information system and technology perspective (Ferraris, Mazzoleni, Devalle \& Couturier, 2019; Nisar, Prabhakar \& Strakova, 2019). Fourthly, there are not many empirical researches that examined the dynamic nature of knowledge management.

The present study utilises Nonaka (1994) original theory of knowledge creation to support the conceptual framework. In this theory, knowledge assets are divided into two constructs; tacit and explicit knowledge. Tacit knowledge begins at individual level and very context specific whilst something that can be written and documented in words and numbers are 
explicit knowledge. The knowledge-based view theory emphasises on the benefits of utilising employees' tacit knowledge for innovation that can sustain competitive advantage (Grant, 1997). In a different sight, they are the knowledge workers that have positive influence on overall organisational performance. With positive commitment through proper organisation career management, these knowledge workers help to boost organisation performance (Jayasingam \& Yong, 2013). Based on the foregoing, the present study has two folds' objectives. The first is to examine the relationship between knowledge assets on innovative performance. Secondly, to test the interaction effects of first, speed and second, reliability as well as accuracy of knowledge transfer on knowledge assets and innovative performance relationship.

\section{Literature review}

\section{Study of Knowledge Management in SMEs}

Until present, most SMEs are found to benefit from knowledge management (Kianto, Hussinki, Vanhala \& Nisula, 2018; Wolf, Kaudela-Baum \& Meissner, 2011), unlike the systematic and sophisticated approaches of knowledge management in large organisations, such as multinational companies (Blomkvist, 2012) or even hospitals (Hosseini, Nikkhah Tekmedash, Karami \& Jabarzadeh, 2019). Many studies have found that knowledge management and organisational performance relationship are positively related in the context of SMEs (Chong et al., 2014; Darroch, 2005; Varis \& Littunen, 2010). Also, knowledge management practices and performance relationship has been found to have more significant effects on performance in SMEs (Sawaean \& Ali, 2020). This is further supported as most studies have found that smaller organisations to be significantly moderate the relationship between knowledge management and process improvement in a quantitative study of 180 knowledge-based organisations in Malaysia (Jayasingam, Ansari, Ramayah \& Jantan, 2012).

SMEs with its liability size have flat structure, and flexible management style that is more informal, non-bureaucratic as well as relax. The distance between top management team and employees is narrow as well as reduce communication barriers between them. This increases the frequencies of informal discussions and most likely increases the potential development of innovative ideas. Usually, knowledge management are more likely related to information systems and data sharing. However, SMEs prefer to manage tacit knowledge as compared to explicit knowledge even though they always loss knowledge when organisation members resign. This occurs through lots of discussions, frequent and friendly communication among employees in SMEs. Hence, for SMEs to gain full advantages from knowledge management practices, appropriate process needs to be implemented. For example, in a study on the impact of innovation on growth and performance of processes food SMEs in Malaysia, a significant positive impact was found (Alam, Bhuiyan, Jani \& Wel, 2016). The following subsections further explain about the constructs developed pertaining to knowledge assets, knowledge transfer, and innovative performance.

\section{Knowledge assets and innovative performance}

Knowledge assets represent strategic resources and sources of value creation (Schiuma, Carluci \& Sole, 2012). When we look at the relationship between knowledge assets and innovative 
performance, it relates to the association with organisation's sustainable competitive advantage. Although, knowledge assets are literally divided into two main elements; tacit and explicit. Tacit knowledge has the dynamic characteristics (Teece, 2000) that is most likely to have positive effect on performance. Barney's RBV characteristic of resources that increase competitive advantage, which explains that employees' knowledge is the resources that possess the valuable element where they can help bring the organisation in sustaining competitive advantages (Barney, 1995).

The dynamic of knowledge assets positively influences innovative performance mainly through organisational learning, and teamwork. Meanwhile, organisational learning mechanism elevates the value of knowledge assets as it is utilised for competitive advantage. Through learning, employees are trained to develop their current knowledge, skills and abilities to another level. This is one of the examples of tacit knowledge in employees' mind. Learning process mostly occurs during training and development activities. Training and development schemes that improve skills also increase employees' value as a strategic asset, especially when on-thejob training is organisation specific. By definition, organisation-specific training equips employees with skills which are not easily transferable to other employers.

Besides, investment in employees' skills increase their ability to come out with new innovative ideas and sustain competitive advantage as more time is needed for competitors to upskill their workforce to the same level. With learning, employees' knowledge, skills, and abilities are improved. This development leads to their ability to think wisely and become more creative at work. With proper brainstorming sessions, employees' creativity will contribute to more ideas for innovation. With the right time, resources and capabilities, organisations especially SMEs can take up these innovation opportunities. Such programs can positively impact innovation and employee's performance.

Secondly, teamwork is the second mechanism through which knowledge assets impacts innovative performance positively. When employees work in teams, more ideas are generated through discussions and brainstorming sessions. Previous studies have proven that with proper management of teams and groups in organisations, more creative ideas can be generated for innovation (Ganguly, Chatterjee \& Farr, 2017; Grigoriou \& Rothaermel, 2013; Mihalache, Justin, Bosch \& Henk, 2012). This is because the intangible knowledge asset, which is the tacit knowledge in employees' mind, will no doubt turn to explicit knowledge through team's brainstorming session. As such, the evaluation of knowledge assets is important when employees identify, classify and measure the ideas that are considered as knowledge assets (Lerro et al., 2012). Therefore, the present study aims to link a positive relationship between knowledge assets and innovative performance.

H1: Knowledge assets have a positive relationship with innovative performance

\section{Interaction effects of Knowledge Transfer on Knowledge Assets and Innovative Performance Relationship.}

The movement of knowledge from one unit to another in an organisation is known as knowledge transfer (Argote \& Ingram, 2000; Rui et al., 2016). Usually, this process involves people as intermediaries for the knowledge or information to be transferred to another (Syed-Ikhsan \& Rowland, 2004b). In the era of millennial, the transfer of information and knowledge are so fast. In recent time, knowledge is transfer from speed, reliability, and its accuracy perspectives. Thus, 
the present study proposes the mechanism that knowledge transfer has positive interaction effect on the association of knowledge assets and innovative performance. The mechanisms that explain these moderating effects are through the effect of using technology and information system as well as by having the right culture.

The first mechanism through which speed of knowledge transfer would positively influence knowledge assets and innovative performance could be due to the use of technology. Technology like computers, laptop and even smart phones are always mentioned as the solution for knowledge transfer. It is the easiest and fastest way of communication among employees in most organisations. In the industrial revolution 4.0, information may spread instantly with smart phones. Until now, there are many communication applications in Apple app or Google play store available for business usage. For example, WhatsApp and Telegram applications have been used widely in most business organisation in Malaysia, especially SMEs. Although, it is cheap, yet very efficient in transferring knowledge and information. As such, the use of technology with information system improves the management of knowledge assets and acts as an important system in capturing valuable explicit knowledge that can be utilised for innovation.

Secondly, the culture of the organisation is also the mechanism through which knowledge is transferred positively to moderate the aforementioned relationship. However, culture is a broad concept that has many dimensions. Co-operation and collaboration are two of the cultural dimensions that increase the dynamic of knowledge transfer (Goh, 2002). For knowledge transfer to occur, it requires a group of employees to work in a team or group for knowledge sharing. This reflects that for knowledge transfer to occur in an organisation, employees need to be cooperative among themselves, thus lead to knowledge sharing and collaboration among one another. Therefore, knowledge is transfer through positive utilising the right technology and information system while having co-operative and collaborative culture to moderate knowledge assets as well as innovative performance relationship.

Thirdly, the absorptive capacity of the organisation also plays an important role through which knowledge transfer positively moderates knowledge assets and innovative performance relationship. Awang, Hussain, \& Malek, (2013) found that the success of knowledge transfer depends on absorptive capacity and organisational learning climate. Furthermore, Escribano, Fosfuri and Tribó, (2009) and Martínez-Sánchez et al. (2020) argued that organisations with higher level of absorptive capacity positively stimulate innovative outcomes. Based on these three arguments on the mechanisms, the following hypotheses are developed:

H2(a): The speed of knowledge transfer positively moderate knowledge assets and innovative performance relationship.

H2(b): Reliability and accuracy of knowledge transfer positively moderate knowledge assets and innovative performance relationship. 


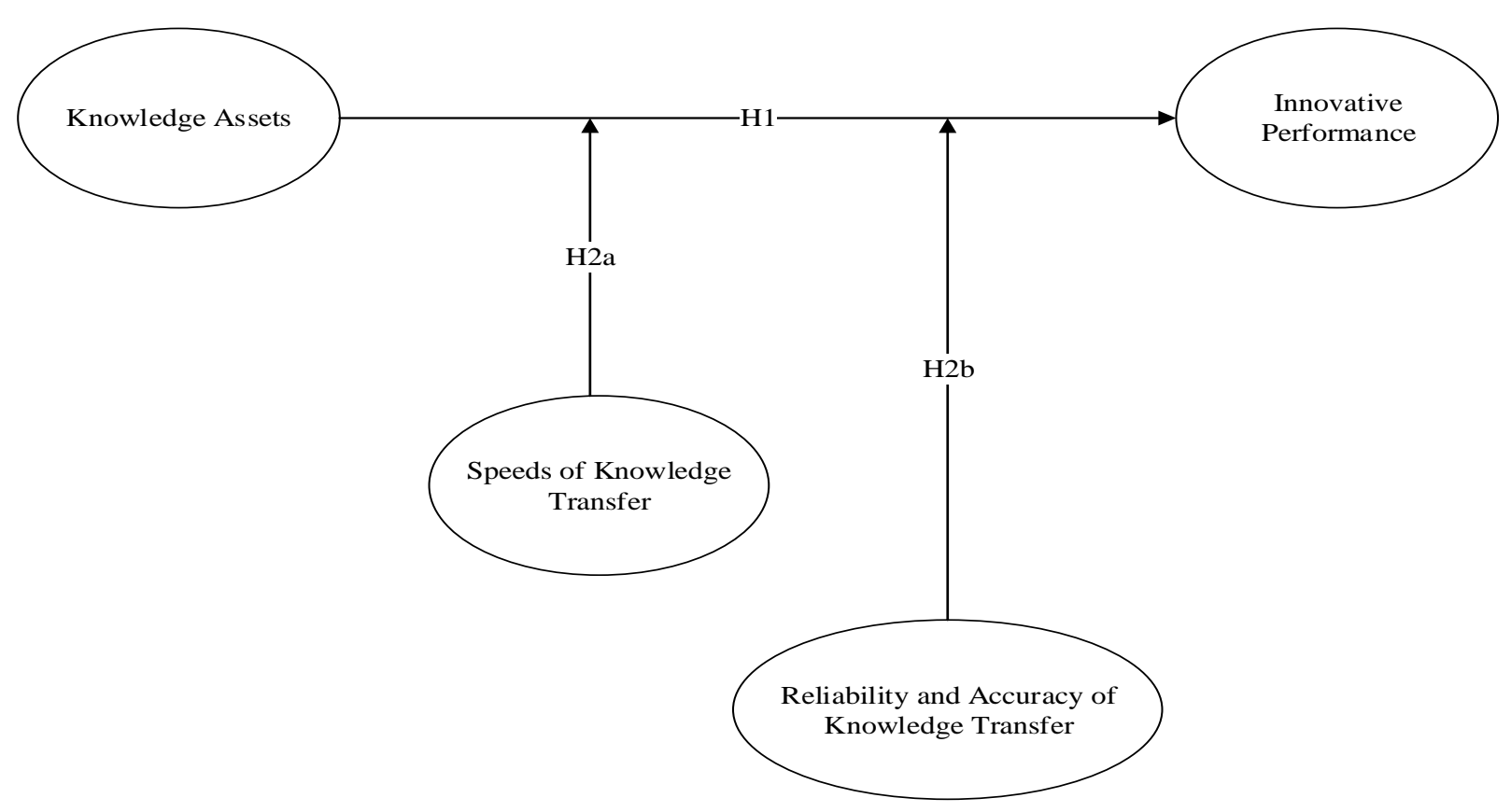

Figure 1. Research model

\section{Methodology}

The present study is a quantitative research exploring the perception of CEOs' and owner managers of Malaysian SMEs on knowledge assets, knowledge transfer, and innovative performance. The sampling frame consists of Malaysian SMEs that have registered with SMECorp Malaysia (the government agency that manages all SMEs in Malaysia). The online surveys were distributed using QUALTRICS software. E-mail messages containing the link to online survey link were sent to more than 1000-targeted respondents' email addresses, which was made for 6 months period. Finally, responds from 144 SMEs were ready for analysis as the response rate can be consider as good at $15 \%$ compared to other studies in the same context of Malaysian SMEs.

\section{Scale of measurements}

There are four sections in the questionnaires. The first section covers the knowledge assets that consist of where explicit and tacit knowledge assets are taken from (Syed-Ikhsan \& Rowland, 2004a, 2004b). There are four items representing knowledge assets. The second section, shows items in knowledge transfer taken from Rhodes, Hung, Lok, Lien \& Wu, (2008). Speed of knowledge transfer has four items while; reliability and accuracy of knowledge transfer have five items. The third section shows the present study adopts six innovative performance measures taken from Alegre, Sengupta and Lapiedra (2011). The fourth section depict control variables for the present study, which are; age, total employees, type of industry, sales turnover, and whether the company is certified 1-innoCERT or not. This certification is provided to innovative Malaysian SMEs. 


\section{Results and discussion}

\section{Descriptive Analysis}

Out of 189 respondents that answered the online survey, only 144 answers were usable. The present study looks at the organisational level where the respondents are mainly CEOs, senior management team, as well as senior HR managers. These companies are compared across size, industry type, number of employees as well as whether they are certified as innovative (1InnoCERT certification) or not. The types of industries for the present study are the ones that follow the Standard Industrial Classification (SIC) codes. Additionally, mining industry is excluded from the analysis dataset to prevent the potential dummy variable trap. This always happen when one or more variables are highly correlated, and the independent variables are multicollinear. In addition to the aforementioned approach, the present study addresses the common method variance through Harman one factor analysis. The result indicates no common method variance.

\section{Normality and Data Transformation}

The normality and data transformation were analysed using SPSS25. Transformations were done to only highly skewed items in normality plot. Finally, variables of the present study are knowledge assets, innovative performance, speed of knowledge transfer, and reliability and accuracy of knowledge transfer.

\section{Results of Testing Hypotheses}

In order to test the model hypothesis in the present study, two stages of analysis were performed. Firstly, an exploratory factorial analysis was performed in order to identify a clear factor structure among the research variables, and which variable gives a major contribution to represent each construct. Table 1 shows the factor loading for each construct. The correlation between items and factors loading are adequate as they are greater than 0.5 (Henseler, Ringle \& Sinkovics, 2009). The result of the factor analysis indicates a valid research model.

Table 1. The results for factor loadings for different constructs

\begin{tabular}{lcccc}
\hline Construct or items & KT-RA & KT-S & IP & KA \\
\hline KT - Reliability \& accuracy & & & & \\
KTR3R $\log 10$ & 0.832 & & \\
KTR2Rlog10 & 0.803 & & \\
KTR1Rlog10 & 0.764 & 0.355 & \\
KAT1Rlog10 & 0.676 & & \\
KTA2Rlog10 & 0.661 & 0.432 & \\
KTA1Rlog10 & 0.642 & 0.37 & \\
KT - Speed & & & \\
KTS2Rlog10 & & 0.908 & \\
KTS4R $\log 10$ & & 0.888 & \\
KTS1R $\log 10$ & & 0.862 & \\
KTS3R $\log 10$ & & 0.854 & \\
Innovative performance & & &
\end{tabular}




\begin{tabular}{lll} 
InnovativeP3R $\log 10$ & 0.837 & \\
InnovativeP2R $\log 10$ & 0.826 & \\
InnovativeP4R $\log 10$ & 0.765 & \\
InnovativeP5R $\log 10$ & 0.731 & 0.33 \\
InnovativeP6Rlog10 & 0.717 & \\
InnovativeP1Rlog10 & 0.639 & \\
Knowledge assets & & \\
KAE1Rlog10 & 0.783 \\
KAE2Rlog10 & 0.74 \\
KAT2Rlog10 & 0.593 \\
\hline Extraction Method: Principal Component Analysis. & \\
Rotation Method: Varimax with Kaiser Normalization. & & \\
a Rotation converged in 6 iterations. &
\end{tabular}

As shown in Table 2, knowledge assets are correlated with innovative performance $(\mathrm{r}=0.369, \mathrm{p}$ $<0.01)$ as well as speed $(\mathrm{r}=447, \mathrm{p}<0.01)$ and accuracy and reliability $(\mathrm{r}=0.656, \mathrm{p}<0.01)$. Also, it negatively correlated with agricultural industry $(\mathrm{r}=-.188, \mathrm{p}<.05)$ and positively correlated with finance industry $(\mathrm{r}=.171, \mathrm{p}<0.05)$. The speed of knowledge transfer also correlated with knowledge assets $(r=0.447, \mathrm{p}<0.01)$ reliability and accuracy of knowledge transfer $(\mathrm{r}=.617, \mathrm{p}<0.01)$ as well as innovative performance $(\mathrm{r}=.337, \mathrm{p}<0.01)$.

On the other hand, reliability and accuracy of knowledge transfer positively correlate with knowledge assets $(\mathrm{r}=.646, \mathrm{P}<0.01)$, speed of knowledge transfer $(\mathrm{r}=.617, \mathrm{p}<0.01)$ and innovative performance $(\mathrm{r}=.413, \mathrm{p}<0.01)$ and manufacturing industry $(\mathrm{r}=.173, \mathrm{p}<0.05)$. Lastly, innovative performance also correlates with knowledge assets $(r=.369, \mathrm{p}<0.01)$, speed of knowledge transfer $(\mathrm{r}=.337, \mathrm{p}<0.01)$, reliability and accuracy of knowledge transfer $(\mathrm{r}=$ $.413, \mathrm{p}<0.01)$ as well as innovative SMEs $(\mathrm{r}=.224, \mathrm{p}<0.01)$.

In addition to the correlations, number of employees is positively correlated with age $(\mathrm{r}=$ $.447, \mathrm{p}<0.01)$, sales turnover of the company are positively correlated with age $(\mathrm{r}=.306, \mathrm{p}$ $<.01)$ and number of employees $(\mathrm{r}=.401, \mathrm{p}<.01)$. Agricultural industry positively correlates with innovative SMEs $(\mathrm{r}=.181, \mathrm{p}<.05)$. On the other hand, service industry negatively correlates with age of the company $(\mathrm{r}=-.165, \mathrm{p}<0.05)$, agricultural industry $(\mathrm{r}=-.174, \mathrm{p}<$ $0.05)$, manufacturing industry $(\mathrm{r}=.-645, \mathrm{p}<0.05)$. Furthermore, the present study tests the hypotheses using multiple regression analysis.

Conversely, Table two indicates the mean values of all the variables. The mean for companies' age is 14 years, indicating that most organisations that involved in the present study are already established for a long time. In terms of number of employees, mean of 72 people indicate that respondents in the present study are organisations that have quite a number of employees from services and manufacturing industry. 
Table 2. Descriptive statistics and correlations

\begin{tabular}{|c|c|c|c|c|c|c|c|c|c|c|c|c|c|c|c|c|c|c|c|}
\hline & Variables & Mean & SD & 1 & 2 & 3 & 4 & 5 & 6 & 7 & 8 & 9 & 10 & 11 & 12 & 13 & 14 & 15 & 16 \\
\hline 1 & $\begin{array}{l}\text { Innovativ } \\
\text { e SMEs }\end{array}$ & 0.28 & 0.45 & 1 & -0.060 & -0.034 & -0.021 & $.181^{*}$ & -0.074 & 0.064 & 0.059 & -0.118 & 0.135 & 0.019 & $\overline{0}-\overline{0}$ & 0.120 & $-\overline{0}$ & $\overline{0}-\overline{0}$ & $.224^{* *}$ \\
\hline 2 & Age & 14.34 & 9.01 & -0.060 & 1 & $.447^{* *}$ & $.306^{* *}$ & 0.066 & -0.031 & 0.101 & 0.042 & 0.056 & -0.106 & $-.165^{*}$ & 0.114 & - & $\begin{array}{l}- \\
0.104\end{array}$ & $\begin{array}{l}- \\
0.154\end{array}$ & -0.113 \\
\hline 3 & $\begin{array}{l}\text { Employe } \\
\text { es }\end{array}$ & 72.17 & 92.74 & -0.034 & $.447^{* *}$ & 1 & $.401^{* *}$ & $-\overline{0.083}$ & -0.078 & 0.046 & -0.052 & -0.007 & -0.058 & 0.020 & 0.034 & - & - & - & 0.057 \\
\hline 4 & Sales & $\begin{array}{l}2749248 \\
7\end{array}$ & $\begin{array}{l}4770484 \\
1\end{array}$ & -0.021 & $.306^{* *}$ & $.401^{* *}$ & 1 & $-\overline{0.096}$ & -0.054 & -0.081 & -0.044 & -0.009 & -0.043 & 0.033 & 0.037 & 0.001 & 0.102 & 0.079 & 0.071 \\
\hline 5 & Agri & 0.04 & 0.20 & $.181^{*}$ & 0.066 & -0.083 & -0.096 & 1 & -0.025 & -0.162 & -0.025 & -0.040 & -0.017 & $-.174^{*}$ & $\overline{0}-\mathbf{0} 0$ & $-188^{*}$ & $\begin{array}{l}- \\
0.074\end{array}$ & $-\overline{0.133}$ & 0.033 \\
\hline 6 & Const & 0.01 & 0.12 & -0.074 & -0.031 & -0.078 & -0.054 & $\overline{-}-025$ & 1 & -0.092 & -0.014 & -0.023 & -0.010 & -0.099 & $-\overline{0.017}$ & $\begin{array}{l}- \\
0.004\end{array}$ & $\begin{array}{l}- \\
0.098\end{array}$ & 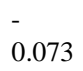 & -0.028 \\
\hline 7 & Manuf & 0.38 & 0.49 & 0.064 & 0.101 & 0.046 & -0.081 & $-\overline{0.162}$ & -0.092 & 1 & -0.092 & -0.147 & -0.065 & $-.645^{* *}$ & - & 0.082 & 0.024 & 0.009 & -0.076 \\
\hline 8 & Trans & 0.01 & 0.12 & 0.059 & 0.042 & -0.052 & -0.044 & 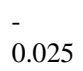 & -0.014 & -0.092 & 1 & -0.023 & -0.010 & -0.099 & 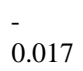 & $\begin{array}{l}- \\
0.037\end{array}$ & 0.003 & $-\overline{0.026}$ & -0.090 \\
\hline 9 & $\begin{array}{l}\text { Wholesal } \\
\mathrm{e}\end{array}$ & 0.03 & 0.18 & -0.118 & 0.056 & -0.007 & -0.009 & 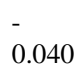 & -0.023 & -0.147 & -0.023 & 1 & -0.016 & -0.158 & $\overline{-}-028$ & $\begin{array}{l}- \\
0.033\end{array}$ & 0.063 & 0.008 & -0.005 \\
\hline 10 & Finance & 0.01 & 0.08 & 0.135 & -0.106 & -0.058 & -0.043 & $-\overline{0}$ & -0.010 & -0.065 & -0.010 & -0.016 & 1 & -0.070 & $\overline{-}-12$ & $.171^{*}$ & 0.133 & $.173^{*}$ & 0.100 \\
\hline 11 & Service & 0.41 & 0.49 & 0.019 & $-.165^{*}$ & 0.020 & 0.033 & $-.174^{*}$ & -0.099 & $-.645^{* *}$ & -0.099 & -0.158 & -0.070 & 1 & $-\overline{0.122}$ & 0.113 & $\begin{array}{l}- \\
0.034\end{array}$ & 0.142 & 0.108 \\
\hline 12 & Public & 0.02 & 0.14 & -0.090 & 0.114 & 0.034 & 0.037 & $-\overline{0.030}$ & -0.017 & -0.113 & -0.017 & -0.028 & -0.012 & -0.122 & 1 & $\begin{array}{l}- \\
0.098\end{array}$ & 0.100 & $-\overline{0.065}$ & -0.066 \\
\hline 13 & KA & 0.75 & 0.01 & 0.120 & -0.116 & -0.005 & 0.001 & $-.188^{*}$ & -0.004 & 0.082 & -0.037 & -0.033 & $.171^{*}$ & 0.113 & $-\overline{0}$ & 1 & $.447^{* *}$ & $.646^{* * *}$ & $.369^{* *}$ \\
\hline 14 & KT-S & 0.81 & 0.01 & -0.095 & -0.104 & -0.059 & 0.102 & $\begin{array}{l}- \\
0.074\end{array}$ & -0.098 & 0.024 & 0.003 & 0.063 & 0.133 & -0.034 & 0.100 & $.447^{* *}$ & 1 & $.617^{* *}$ & $.337^{* *}$ \\
\hline 15 & KT-R & 0.76 & 0.01 & -0.002 & -0.154 & -0.044 & 0.079 & $-\overline{0.133}$ & -0.073 & -0.009 & -0.026 & 0.008 & $.173^{*}$ & 0.142 & $\overline{-} .065$ & $.646^{* *}$ & $.617^{* *}$ & 1 & $.413^{* *}$ \\
\hline 16 & $\begin{array}{l}\text { Inno. } \\
\text { Perf }\end{array}$ & 4.97 & 0.96 & $.224^{* *}$ & -0.113 & 0.057 & 0.071 & 0.033 & -0.028 & -0.076 & -0.090 & -0.005 & 0.100 & 0.108 & 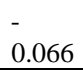 & $.369^{* *}$ & $.337^{* *}$ & $.413^{* *}$ & 1 \\
\hline
\end{tabular}

** Correlation is significant at the 0.01 level.

* Correlation is significant at the 0.05 level. 
Table 3 shows the results for all the hypotheses after controlling for innovative SMEs, companies' age, number of employees, sales turnover and industries. Model 1 in table 3 indicate no significant support for all the control variables $[\mathrm{F}(12,131)=1.232, \mathrm{p}=0.268]$. However, model $2[\mathrm{~F}(1,130)=18.323, \mathrm{p}<.000]$ is statistically significant $(\beta=0.212, p<0.001)$ and explains $21 \%$ of the variance in innovative performance. The results indicate supporting evidence for hypothesis $1(\beta=0.357, p<0.001)$. There is positive relationship between knowledge assets and innovative performance. Next, the study looked into the moderating effect of speed of knowledge transfer in the relationship of knowledge assets with innovative performance (hypothesized as $\mathrm{H} 2 \mathrm{a}$ ) and the moderating effect of reliability as well as accuracy of knowledge transfer in the relationship of knowledge assets with innovative performance (hypothesized as $\mathrm{H} 2 \mathrm{~b}$ ). According to Table 3, under Model $3[\mathrm{~F}(2,128)=6.219, \mathrm{p}<.001]$ there is a positive interaction effects of speed $(\beta=0.315, p<0.001)$, reliability and accuracy of knowledge transfer $(\beta=0.36, \mathrm{p}<0.05)$ on knowledge assets and innovative performance relationship. As such, the present study concludes that, hypotheses $\mathrm{H} 2 \mathrm{a}$ and $\mathrm{H} 2 \mathrm{~b}$ were supported.

Table 3. Results of multiple regression

\begin{tabular}{llll}
\hline & Model 1 & Model 2 & Model 3 \\
\hline Innovative SMEs & $0.214^{*}$ & $0.182^{*}$ & 0.236 \\
Age & -0.147 & -0.116 & -0.076 \\
Employees & 0.102 & 0.099 & 0.126 \\
Sales & 0.078 & 0.061 & 0.001 \\
Agri & 0.021 & 0.049 & 0.025 \\
Const & -0.003 & -0.027 & 0.004 \\
Manuf & -0.041 & -0.154 & -0.175 \\
Trans & -0.085 & -0.095 & -0.109 \\
Wholesale & 0.031 & 0.001 & -0.023 \\
Finance & 0.066 & -0.004 & -0.037 \\
Service & 0.049 & -0.066 & -0.085 \\
Public & -0.034 & -0.033 & -0.062 \\
KA & & $-0.357 * * *$ & -0.236 \\
KT-S & & & $0.315 *$ \\
KT-R & & & $0.360^{* *}$ \\
\hline $\mathrm{R}^{2}$ & & $0.212^{* * *}$ & $0.282^{* * *}$ \\
Change in $\mathrm{R}^{2}$ & 0.101 & 0.111 & 0.7 \\
\hline Notes: $\mathrm{N}-144$, Standardised coefficients are reported. Significant level *p $<0.1, * * \mathrm{p}<.05, * * * \mathrm{p}<.01$
\end{tabular}

Table 4. Hypotheses testing

\begin{tabular}{clccc}
\hline \multicolumn{1}{c}{ Relationship } & Std. Beta & p-value & Results \\
\hline H1 & $\begin{array}{l}\text { Knowledge assets } \\
\rightarrow \text { innovative performance }\end{array}$ & 0.357 & 0.001 & Supported \\
H2a & $\begin{array}{l}\text { Knowledge assets * Speed of knowledge transfer } \rightarrow \\
\text { Innovative performance }\end{array}$ & 0.315 & 0.001 & Supported \\
H2b & $\begin{array}{l}\text { Knowledge assets * Reliability and accuracy of } \\
\text { knowledge transfer } \rightarrow \text { Innovative performance }\end{array}$ & 0.360 & 0.05 & Supported \\
\hline
\end{tabular}


In understanding the knowledge transfer-innovative performance of SMEs, the Nonaka's theory of knowledge creation and knowledge-based view theory are ideal and critical. It provides the empirical evidence upon which SMEs can base the mechanism of knowledge transfer in order to achieve innovative performance. The present study showed that knowledge transfer is a crucial factor in determining innovative performance. This finding corroborates with past studies which has proposed that knowledge assets could influence innovative performance and sustainability (Omar, Md Aris \& Nazri, 2016; Singh et al., 2020). This also supports the idea by Akgün et al. (2007) and Pérez-Luño et al. (2019) that communication, interactions, discussions, and value co-creation among SMEs owner with employees and other stakeholders could lead to competitive advantage and innovation. Therefore, in order to promote innovation, it is important for SMEs to develop the culture toward knowledge-based view that emphasises on team works and commitment in upgrading the employees' skills for innovation and firm sustainability (Delgado-Verde, Martín-de Castro \& Navas-López, 2011; De Silva et al., 2018; Ganguly, Chatterjee \& Farr, 2017; Wu, Liu, Zhang \& Yu, 2019).

In addition, there are two surprising findings in the present study. Firstly, the speed of knowledge transfer is found to be positively moderate knowledge assets and innovative performance. The interaction between knowledge assets and innovative performance is being enhanced by the speed of knowledge transfer. Secondly, the study also observed that reliability and accuracy of knowledge transfer positively moderate knowledge assets and innovative performance. The interaction between knowledge assets and innovative performance is being enhanced by the reliability and accuracy of knowledge transfer. The findings strengthened the Barney's RBV characteristic of resources that intangible resources are scarce, difficult to trade, and imitate. Stemming from the RBV, organizational knowledge which is a kind of intangible resource that has the same characteristics as strategic resources which depend on the knowledge environment as the main driver in promoting innovation (Wu et al., 2019). Thus, the present study further supported that innovative performance was strongly dependent on the speed, reliability and accuracy of knowledge transfer.

Also, speed, reliability and accuracy of knowledge transfer denote a condition of knowledge transfer mechanism and characteristics, which indicate that high speed and accurate knowledge are more likely to be accepted by SMEs, stakeholders and therefore a vital contingent context for greater resource inflows as well as innovation. Other than this, the present study further developed a multi-theoretical research model using the nonaka theory of knowledge creation and knowledge-based view theory for understanding the relationships among knowledge assets, speed of knowledge transfer, reliability and accuracy of knowledge transfer, as well as innovative performance. By inaugurating a link between these two theories, the model is not only valuable in providing sufficient explanatory opportunities but is also of importance for SMEs' top management in addressing innovative performance from multiple perspectives of knowledge transfer mechanism to make their business to take advantage of opportunities.

\section{Conclusion}

The present study emphasises that knowledge transfer can elevate the effect of knowledge assets management on innovative performance. This confirms the study of knowledge transfer in public organisations (Salleh, Chong, Syed Ahmad \& Syed Ikhsan, 2012; Syed-Ikhsan \& Rowland, 2004a, 2004b). Furthermore, in comparison to public organisations, SMEs are capable of being 
more innovative when knowledge assets are managed properly. This is because the urge to be creative and innovative is more stressful in SMEs compared to public organisations due to different organisational cultural practises in the SMEs. According to resource-based view theory, high level of competitions among SMEs enforces them to find the best strategies and practices in sustaining competitive advantages. Thus, proper management of knowledge assets is found to be practical and has stronger relationship to innovative performance in SMEs compared to public organisations. However, this does not mean that the requirement to be innovative are less needed in public organisations, but the difference in organisational goal differentiates the effect of innovative performance between these two types of organisations.

\section{Practical and Managerial Implications}

In the present study, the results indicate that speed, accuracy, and reliability of knowledge transfer positively influence knowledge assets and innovative performance. Firstly, proper management of knowledge assets make them unique for competitors to imitate, which elevates the overall values of innovative products and services. Secondly, strategies related to knowledge management shall focus on the identification of knowledge inside the SMEs and provide guidelines to employees on how to utilise them. Thirdly, with regard to the management of knowledge transfer, SMEs should try to implement proper knowledge management strategy so that the flow of knowledge among employees can be made to be more systematic where all employees are enabled to access all kind of knowledge and information available in the organisation. Therefore, it is essential for SMEs to formulate strategies to assess knowledge assets.

\section{Limitation and Future Studies}

Although the objectives of the present research were addressed, but there are certain limitations that should be considered before generalising the findings. These limitations can also be a starting point for future studies. Firstly, the data was collected from SMEs, thus the results are not applicable to large firms. As such, further research is needed on other type of organisations. Secondly, the study data were limited to Malaysia, which makes requires further studies to test the model on other countries, either developed countries as well as developing ones. Lastly, the present study only employed the quantitative data of knowledge assets; innovative performance and knowledge transfer from online survey and disregards the qualitative aspects of knowledge assets, innovative performance and knowledge transfer constructs. Therefore, future research may be conducted to overcome these limitations.

\section{Acknowledgement}

Financial support from Centre of Research and Instrumental (CRIM-UKM-GGPM 2018-002), and from Faculty of Economics and Management, Universiti Kebangsaan Malaysia is acknowledged.

\section{References}

Ahmad, K., JianMing, Z., \& Rafi, M. (2019). Assessing the literature of knowledge management 
$(\mathrm{KM})$ in the field of library and information science. Information Discovery and Delivery, 47(1), 35-41.

Akgün, A.E., Keskin, H. and Aren, S. (2007). Emotional and learning capabilities and their impact on product innovativeness and firm performance. Technovation, 27(9), 501-13.

Alam, S. S., Bhuiyan, A. B., Jani, F. M., \& Wel, C. A. C. (2016). The impact of innovation on growth and performance of processed food SMEs in Malaysia. International Journal of Entrepreneurship and Innovation Management, 20(1-2), 61-79.

Alegre, J., Sengupta, K., \& Lapiedra, R. (2011). Knowledge management and innovation performance in a high-tech SMEs industry. International Small Business Journal, 31(4), 454-470.

Alexander, A. T., Neyer, A.-K., \& Huizingh, K. R. E. (2016). Introduction to the special issue: transferring knowledge for innovation. $R \& D$ Management, 46(2), 305-311.

Amin, S., Usman, M., Sohail, N., \& Aslam, S. (2018). Relationship between intellectual capital and financial performance: The moderating role of knowledge assets. Pakistan Journal of Commerce and Social Sciences (PJCSS), 12(2), 521-547.

Awang, A. H., Hussain, M. Y., \& Malek, J. A. (2013). Knowledge transfer and the role of local absorptive capability at science and technology parks. Learning Organization, 20(4-5), 291-307.

Barney, J. B. (1995). Looking inside for competitive advantage. Academy of Management Perspectives, 9(4), 49-61.

Bhuiyan, A. B., Said, J., Jani, M. F. M., \& Fie, D. Y. G. (2017). The innovation drivers, strategies and performance of food processing SMEs in Malaysia. Geografia-Malaysian Journal of Society and Space, 12(2), 154-166.

Blomkvist, K. (2012). Knowledge management in MNCs: the importance of subsidiary transfer performance. Journal of Knowledge Management, 16(6), 904-918.

Chen, I. W. J., Wu, I., \& Chen, J. (2014). Knowledge management driven firm performance : the roles of business process capabilities and organizational learning. Journal of Knowledge Management, 18(6), 1141-1164.

Chong, A. Y.-L., Ooi, K.-B., Bao, H., Lin, B., Yee-Loong Chong, A., Ooi, K.-B., ... Lin, B. (2014). Can e-business adoption be influenced by knowledge management? An empirical analysis of Malaysian SMEs. Journal of Knowledge Management, 18(1), 121-136.

Chung, J. Y., \& Yoon, W. (2015). Social Facets of Knowledge Creation: The Validation of Knowledge Assets. Social Behavior and Personality: An International Journal, 43(5), $815-827$.

Darroch, J. (2005). Knowledge management, innovation and firm performance. Journal of Knowledge Management, 9(3), 101-115.

Delgado-Verde, M., Martín-de Castro, G., \& Navas-López, J. E. (2011). Organizational knowledge assets and innovation capability. Journal of intellectual capital, 12(1), 5-19.

De Silva, M., Howells, J., \& Meyer, M. (2018). Innovation intermediaries and collaboration: Knowledge-based practices and internal value creation. Research Policy, 47(1), 70-87.

Department of Statistics Malaysia (2011), "Economic Census 2011-profile of small and mediumenterprises", Retreived from http://www.dosm.gov.my/v1/index.php?r=column/ cone\&menu_id=T2pLUVNDNFh2UGw5azJvYzRJOWFMZz09

Escribano, A., Fosfuri, A., \& Tribó, J. A. (2009). Managing external knowledge flows: The moderating role of absorptive capacity. Research Policy, 38(1), 96-105.

Estrada, I., Faems, D., \& de Faria, P. (2014). Coopetition and product innovation performance: 
The role of internal knowledge sharing mechanisms and formal knowledge protection mechanisms. Industrial Marketing Management, 53, 56-65.

Ferraris, A., Mazzoleni, A., Devalle, A., \& Couturier, J. (2019). Big data analytics capabilities and knowledge management: impact on firm performance. Management Decision, 57(8), 1923-1936.

Ganguly, A, Chatterjee, D., \& Farr, J. V. (2017). Evaluating Barriers To Knowledge Sharing Affecting New Product Development Team Performance. International Journal of Innovation Management, 22(06), 1850048.

Gast, J., Gundolf, K., Harms, R., \& Matos Collado, E. (2019). Knowledge management and coopetition: How do cooperating competitors balance the needs to share and protect their knowledge? Industrial Marketing Management, (October 2018), 1-10.

Goh, S. C. (2002). Managing effective knowledge transfer: an integrative framework and some practice implications. Journal of Knowledge Management, 6(1), 23-30.

Grant, R. M. (1996a). Prospering in Dynamically-Competitive Environments: Organizational Capability as Knowledge Integration. Organization Science, 7(4), 375-387.

Grant, R. M. (1996b). Toward a Knowledge-Based Theory of the firm. Strategic Management Journal, 17(s2), 109-122.

Hasan, H, Hamzah, N, Saleh, N.M, \& Kamaluddin, A. (2019). The Effect of Transformational Leadership Styles Towards Managing Knowledge Assets. Asian Journal of Accounting and Governance, 11, 171-180.

Hosseini, S. S., Nikkhah Tekmedash, Y., Karami, A., \& Jabarzadeh, Y. (2019). The Impact of Knowledge Management Strategy on Service Innovation Performance in Private and Public Hospitals. Iranian Journal of Management Studies, 12(1), 1-24.

Jantunen, A. (2005). Knowledge-processing capabilities and innovative performance: an empirical study. European Journal of Innovation Management, 8(3), 336-349.

Kianto, A., Hussinki, H., Vanhala, M., \& Nisula, A. M. (2018). The state of knowledge management in logistics SMEs: evidence from two Finnish regions. Knowledge Management Research and Practice, 16(4), 477-487.

Lerro, A., Iacobone, F. a., \& Schiuma, G. (2012). Knowledge assets assessment strategies: organizational value, processes, approaches and evaluation architectures. Journal of Knowledge Management, 16(4), 563-575.

Martínez-Sánchez, A., Vicente-Oliva, S., \& Pérez-Pérez, M. (2020). The relationship between $\mathrm{R} \& \mathrm{D}$, the absorptive capacity of knowledge, human resource flexibility and innovation: Mediator effects on industrial firms. Journal of Business Research, 118, 431-440.

Mihalache, O., Justin, J., Bosch, F. Van Den, \& Henk, V. (2012). Offshoring and Firm Innovation: The Moderating Role of Top Management Team Attributes. Strategic Management Journal, 33(June 2006), 1480-1498.

Nisar, T. M., Prabhakar, G., \& Strakova, L. (2019). Social media information benefits, knowledge management and smart organizations. Journal of Business Research, 94, 264272.

Nonaka, Ijukiro. (1994). A Dynamic Theory of Organizational Knowledge Creation. Organization Science, 5(1), 14-37.

Omar, N.A., Md Aris, H., \& Nazri, M.A. (2016). The effect of entrepreneurial orientation, innovation capability and knowledge creation on firm performance: A perspective on small scale entrepreneur. Jurnal Pengurusan, 48, 187-200. 
Omar, N. A., Kassim, A. S., Shah Alam, S., \& Zainol, Z. (2018). Perceived retailer innovativeness and brand equity: Mediation of consumer engagement. The Service Industries Journal, 1-27.

Pérez-Luño, A., Alegre, J., \& Valle-Cabrera, R. (2019). The role of tacit knowledge in connecting knowledge exchange and combination with innovation. Technology Analysis \& Strategic Management, 31(2), 186-198

Reich, B. H., Gemino, A., \& Sauer, C. (2014). How knowledge management impacts performance in projects: An empirical study. International Journal of Project Management, 32(4), 590-602.

Rhodes, J., Hung, R., Lok, P., Lien, B. Y.-H., \& Wu, C.-M. (2008). Factors influencing organizational knowledge transfer: implication for corporate performance. Journal of Knowledge Management, 12(3), 84-100.

Roxas, B., Battisti, M., \& Deakins, D. (2014). Learning, innovation and firm performance: knowledge management in small firms. Knowledge Management Research \& Practice, 12(4), 443-453.

Rui, H.C., Zhang, M. and Shipman, A. (2016). Relevant knowledge and recipient ownership: Chinese MNCS'knowledge transfer in Africa. Journal of World Business, 51(5), 713-728

Salleh, K., Chong, S. C., Syed Ahmad, S. N., \& Syed Ikhsan, S. O. S. (2012). Learning and knowledge transfer performance among public sector accountants: An empirical survey. Knowledge Management Research \& Practice, 10(2), 164-174.

Sawaean, F. A. A., \& Ali, K. A. M. (2020). The impact of entrepreneurial leadership and learning orientation on organizational performance of SMEs: The mediating role of innovation capacity. Management Science Letters, 10(2), 369-380.

Singh, S. K., Gupta, S., Busso, D., \& Kamboj, S. (2019). Top management knowledge value, knowledge sharing practices, open innovation and organizational performance. Journal of Business Research. in press.

Shujahat, M., Sousa, M. J., Hussain, S., Nawaz, F., Wang, M., \& Umer, M. (2019). Translating the impact of knowledge management processes into knowledge-based innovation: The neglected and mediating role of knowledge-worker productivity. Journal of Business Research, 94, 442-450.

SME Corporation. (2012-2020). SME Masterplan 2012-2020. SME Corporation Malaysia. Retrieved from http://www.smecorp.gov.my/index.php/en/resources/2015-12-21-11-0706/sme-masterplan/book/11-sme-\%20masterplan-english/3-sme-masterpla

Syed-Ikhsan, S. O. S. Bin, \& Rowland, F. (2004a). Benchmarking knowledge management in a public organisation in Malaysia. Benchmarking: An International Journal, 11(3), 238266.

Syed-Ikhsan, S. O. S., \& Rowland, F. (2004b). Knowledge management in a public organization: a study on the relationship between organizational elements and the performance of knowledge transfer. Journal of Knowledge Management, 8(2), 95-111.

Teece, D. J., Pisano, G., \& Shuen, A. (1997). Dynamic Capabilities and Strategic Management. Strategic Management Journal, 18(7), 509-533.

Varis, M., \& Littunen, H. (2010). Types of innovation, sources of information and performance in entrepreneurial SMEs. European Journal of Innovation Management, 13(2), 128-154.

Wolf, P., Kaudela-Baum, S., \& Meissner, J. O. (2011). Exploring innovating cultures in small and medium-sized enterprises: Findings from Central Switzerland. International Small Business Journal, 30(3), 242-274. 